\title{
A fraction from Dojuksan 30\% ethanol extract exerts its anti-inflammatory effects through Nrf2-dependent heme oxygenase- 1 expression
}

\author{
DONG-SUNG LEE ${ }^{1}$, KYOUNG-SU KIM ${ }^{2}$, WONMIN KO ${ }^{2}$, GI-SANG BAE ${ }^{3}$, SUNG-JOO PARK ${ }^{3}$, \\ JUN-HYEOG JANG ${ }^{4}$, HYUNCHEOL $\mathrm{OH}^{2}$ and YOUN-CHUL KIM ${ }^{2}$ \\ ${ }^{1}$ Department of Biomedical Chemistry, College of Health and Biomedical Science, Konkuk University, Chungju 380-701; \\ ${ }^{2}$ College of Pharmacy, and ${ }^{3}$ College of Oriental Medicine and Professional Graduate School of Oriental Medicine, \\ Wonkwang University, Iksan 570-749; ${ }^{4}$ Department of Biochemistry, Inha University \\ School of Medicine, Incheon 400-712, Republic of Korea
}

Received May 4, 2015; Accepted November 24, 2015

DOI: $10.3892 /$ ijmm.2015.2424

\begin{abstract}
Dojuksan is a traditional herbal medicine used in Korea and China to treat urinary diseases. In the present study, we aimed to examine the anti-inflammatory effects of an ethanol solvent extract of Dojuksan and a fraction (by bioassayguided fractionation) derived from this extract, and to elucidate the specific mechanisms involved. The Dojuksan 30\% ethanol extract (DEE) had a more significant and potent anti-inflammatory effect than the Dojuksan water extract (DWE). DEE markedly inhibited the production of inducible nitric oxide synthase (iNOS), cyclooxygenase-2 (COX-2), nitric oxide (NO), prostaglandin $\mathrm{E}_{2}\left(\mathrm{PGE}_{2}\right)$, tumor necrosis factor- $\alpha(\mathrm{TNF}-\alpha)$ and interleukin-1 $\beta$ (IL-1 $\beta)$, as well as nuclear factor- $\kappa \mathrm{B}(\mathrm{NF}-\kappa \mathrm{B})$ binding activity. We found that the anti-inflammatory effects of DEE were mediated by the induction of nuclear factor E2-related factor 2 (Nrf2)-dependent heme oxygenase-1 (HO-1). To further explore the anti-inflammatory effects of DEE, we generated 6 different fractions of DEE. Of these, DEE-5 decreased the production of NO more significantly than the other fractions. DEE-5 also significantly decreased the expression of iNOS and COX-2, and the production of NO, PGE 2 , TNF- $\alpha$ and IL-1 $\beta$. In addition, DEE-5 also significantly increased HO-1 levels; HO-1 significanlty contributed to the inhibitory effects of DEE-5 on the production of pro-inflammatory mediators. In this study, we determined whether the choice of extraction solvent affects the biological activity of Dojuksan, a traditional herbal formula. Our findings demonstrate that DEE and a fraction derived from this extract exerts anti-inflammatory effects
\end{abstract}

Correspondence to: Professor Youn-Chul Kim, College of Pharmacy, Wonkwang University, Shinyoungdong 344-2, Iksan, Jeonbuk 570-749, Republic of Korea

E-mail: yckim@wku.ac.kr

Key words: Dojuksan 30\% ethanol solvent extract, bioassay-guided fraction, anti-inflammation, heme oxygenase-1 through Nrf2-dependent HO-1 expression, and that DEE may thus have greater potential therapeutic application than DWE.

\section{Introduction}

Dojuksan is a traditional herbal prescription medicine used in Korea and China to treat urinary diseases which cause symptoms, such as yellowish-red urine, pain in the phallus, dysuria and stomatitis (1). Dojuksan is composed of 4 medicinal herbs: Rehmanniae radix, Akebia caulis, Glycyrrhizae radix and Phyllostachys folium. Rehmanniae radix (Scrophulariaceae) is the root of Rehmannia glutinosa Libosch. To date, there a number of studies have been conducted on Rehmanniae radix, including its effects on astrocytes (2), fatigue (3), wound healing (4), anemia (5) and nephropathy (6,7). The second ingredient, Akebia caulis (Lardizabalaceae), is the stem of Akebia quinata Decne and has been studied for its anti-nociceptive and anti-inflammatory effects (8), and for its cytotoxicity (9). The third ingredient, Glycyrrhizae radix (Leguminosae), is the root of Glycyrrhiza glabra L. or Glycyrrhiza uralensis Fisch. and it has been suggested that this reduces stress-induced anxiety (10), apoptosis (11), hepatitis C virus replication (12) and inflammation (13). It has also been suggested that it induces growth-hormone release (14) and acts as an antispasmodic (15). Finally, Phyllostachys folium (Gramineae) is the leaf of Phyllostachys nigra and has been shown to protect retinal ganglion cells (16), treat diabetes (17), enhance leukemic cell differentiation (18) and inhibit interleukin (IL)-12 (19).

Lipopolysaccharide (LPS) is a well-known and important pro-inflammatory factor that can cause endotoxemia, shock, and, eventually, multiple organ dysfunction syndromes (20). Stimulation with LPS can induce the expression of pro-inflammatory mediators in macrophages, such as inducible nitric oxide synthase (iNOS), cyclooxygenase (COX)-2, and chemokines (21). In addition, activated macrophages may secrete pro-inflammatory cytokines, including tumor necrosis factor- $\alpha$ (TNF- $\alpha$ ) and IL-1 $\beta$ (22). Prostaglandin $\mathrm{E}_{2}\left(\mathrm{PGE}_{2}\right)$, which is synthesized by the COX enzyme, is the most abundant prostaglandin in the human body and plays many biological roles. $\mathrm{PGE}_{2}$ is an important 
mediator of inflammatory symptoms, including fever and pain. The COX enzyme exists in 2 forms: the constitutive COX-1 form and the inducible cyclooxygenase-2 (COX-2) form (23). It has a variety of effects on various biological processes, including inflammation, pain, tumorigenesis, vascular function, neuronal function, female reproduction, gastric mucosal health and kidney function $(24,25)$. Nitric oxide (NO) is generated by nitric oxide synthases (NOSs), which catalyze the production of $\mathrm{NO}$ and L-citrulline from L-arginine in the presence of nicotinamide adenine dinucleotide phosphate (NADPH)-derived electrons and $\mathrm{O}_{2}$. Compared with neuronal NOS (nNOS) and endothelial NOS (eNOS), iNOS is expressed in many cell types, including macrophages, neutrophils, dendritic cells, endothelial cells and epithelial cells. The NO produced by these reactions is harmful and plays the role of an effector, for example in macrophages $(26,27)$.

Heme oxygenase-1 (HO-1) is the rate-limiting enzyme in the catabolism of heme, a process that leads to the formation of equimolar amounts of the bile pigment biliverdin, free iron and carbon monoxide (CO) $(28,29)$. The degradation of heme is considered critical in cellular defense. It has been suggested that $\mathrm{CO}$ contributes significantly to the anti-inflammatory properties of HO-1 (30). In addition, it is well known that the nuclear translocation of activated nuclear factor E2-related factor 2 (Nrf2) is an important event upstream of HO-1 expression. Nrf2 is required for the expression of some inducible proteins, such as glutathione $\mathrm{S}$-transferases, quinine reductase and HO-1 (31,32). In a previous study (33), Dojuksan was shown to inhibit inflammatory mediators in RAW264.7 cells. However, to the best of our knowledge, no study on the ethanol extracts or beneficial effects of a fraction from Dojuksan, and its specific anti-inflammatory mechanisms, has been undertaken thus far. In the present study, we investigated the effects of an ethanol solvent extract of Dojuksan and a fraction (by bioassay-guided fractionation) derived from this extract and investigated the antiinflammatory mechanisms associated with Nrf2-dependent HO-1 expression. We used the murine macrophage-like cell line, RAW264.7, in order to examine the anti-inflammatory effects and mechanisms of action of Dojuksan extracted using different methods, such as $30 \%$ ethanol extract (DEE) and bioassay-guided fractionation (fraction DEE-5).

\section{Materials and methods}

Preparation of Dojuksan extracts and $\mathrm{MeOH}$ fraction. The herbs that comprise Dojuksan were purchased from the University Oriental Herbal Drugstore (Iksan, Korea) in August 2011, and a voucher specimen was deposited at the Herbarium of the College of Pharmacy at Wonkwang University (Iksan, Korea). The Dojuksan water extract (DWE), and the $30 \%$ ethanol extract (DEE) were both deposited at the Standardized Material Bank for New Botanical Drugs (Wonkwang University). Dojuksan comprised Rehmanniae radix (8 g), Akebia caulis (8 g), Glycyrrhizae radix (8 g) and Phyllostachys folium (8 g). It (32 g) was extracted with either hot water or $30 \%$ ethanol (2 liters of each) for $2 \mathrm{~h}$, and the extracts were concentrated in vacuo to obtain the 30\% ethanol extract (NNMBS308). The 30\% ethanol extract was subjected to $\mathrm{C}_{18}$-functionalized silica gel flash column chromatography and eluted with a stepwise gradient of $0 \%$ (Fr. 1, DEE-1), 20\% (Fr. 2, DEE-2), 40\% (Fr. 3, DEE-3), 60\% (Fr. 4,
DEE-4), 80\% (Fr. 5, DEE-5) and 100\% (Fr. 6, DEE-6) (v/v) of $\mathrm{MeOH}$ in $\mathrm{H}_{2} \mathrm{O}$ (4 ml each) (Fig. 4).

High performance liquid chromatography (HPLC). The solvents used for the extraction and flash column chromatography were reagent grade without further purification, whereas the solvents used for HPLC were of analytical grade. Flash column chromatography was performed using YMC octadecyl-functionalized silica gel $\left(\mathrm{C}_{18}\right)$. HPLC (YOUNGLIN-YL9100; Young Lin Instrument Co., Anyang, Korea) separation was performed using a Shiseido Capcell Pak $\mathrm{C}_{18}$ column (4.6x250 mm and $5 \mu \mathrm{m}$ particle size; Shiseido Co., Ltd., Tokyo, Japan) with a flow rate of $0.7 \mathrm{ml} / \mathrm{min}$, and an injection volume of $20 \mu \mathrm{l}$. The mobile phase was composed of (A) water and (B) acetonitrile, with an applied gradient of 5\% B increasing to $100 \% \mathrm{~B}$ within $60 \mathrm{~min}$. The column was cleaned with $100 \%$ B for $10 \mathrm{~min}$, and the system was then equilibrated for 20 min under starting conditions. The detection wavelengths were adjusted to ELSD, 210 and $254 \mathrm{~nm}$.

Chemicals and reagents. Dulbecco's modified Eagle's medium (DMEM), fetal bovine serum (FBS), and all other tissue culture reagents used, were purchased from Gibco-BRL Co. (Grand Island, NY, USA) unless otherwise stated. Tin-protoporphyrin IX (SnPP), an inhibitor of $\mathrm{HO}$ activity, was obtained from Porphyrin Products (Logan, UT, USA). Lipofectamine ${ }^{\mathrm{TM}} 2000$ was purchased from Invitrogen Life Technologies (Grand Island, NY, USA). Cobalt protophorphyrin IX (CoPP, Cat. no. C1900) and all other chemicals were obtained from Sigma Chemical Co. (St. Louis, MO, USA) unless otherwise indicated. RAW264.7 cells were obtained from the American Type Culture Collection (ATCC; Manassas, VA, USA). Small interfering RNA (siRNA) against Nrf2 and primary antibodies, including those against HO-1 (SC-10789), Nrf2 (SC-722), COX-2 (SC-1745) and iNOS (SC-650), and appropriate secondary antibodies [anti-goat (SC-2768), anti-mouse (SC-2005) and anti-rabbit (SC-2004)] for western blot analysis, were purchased from Santa Cruz Biotechnology, Inc. (Santa Cruz, CA, USA). Enzyme-linked immunosorbent assay (ELISA) kits for PGE $_{2}$, TNF- $\alpha$ and IL-1 $\beta$ were purchased from R\&D Systems (Minneapolis, MN, USA). TLC silica gel 60 F254 aluminum plates were purchased from Merck (Darmstadt, Germany).

Cell culture and viability assay. Cell culture and viability were carried out as previously described (34). The RAW264.7 cells were maintained at $5 \times 10^{5}$ cells $/ \mathrm{ml}$ in DMEM supplemented with $10 \%$ heat-inactivated FBS, penicillin G (100 U/ $\mathrm{ml})$, streptomycin $(100 \mathrm{mg} / \mathrm{ml})$ and L-glutamine $(2 \mathrm{mM})$, and were incubated at $37^{\circ} \mathrm{C}$ in a humidified atmosphere containing $5 \% \mathrm{CO}_{2}$ and $95 \%$ air. The effects of various experimental modulations on cell viability were evaluated by determining mitochondrial reductase function with an assay based on the reduction of tetrazolium salt 3-[4,5-dimethylthiazol-2-yl]2,5-diphenyltetrazolium bromide (MTT) into formazan crystals. The synthesis of formazan is proportional to the number of functional mitochondria in living cells. For the determination of cell viability, $50 \mathrm{mg} / \mathrm{ml}$ MTT solution were added to $1 \mathrm{ml}$ cell suspension $\left(1 \times 10^{5}\right.$ cells $/ \mathrm{ml}$ in 96 -well plates) for $4 \mathrm{~h}$. The formazan synthesized was dissolved in acidic 2-propanol, and the optical density was measured at $590 \mathrm{~nm}$. The optical density of the formazan synthesized in the control 
(untreated) cells was considered to be $100 \%$ cell viability. The majority of experiments were performed using incubation with LPS and samples, alone and in combination, unless stated otherwise. Pretreatment with samples was performed, beginning at $12 \mathrm{~h}$ before the incubation period, and then stimulation with LPS $(1 \mu \mathrm{g} / \mathrm{ml})$ was undertaken.

Determination of nitrite production, and $P G E_{2}, T N F-\alpha$ and $I L-1 \beta$ assays. The production of nitrite in the conditioned medium was determined using a method based on the Griess reaction, as described in a previous study (35). An aliquot (100 $\mu \mathrm{l})$ of each supernatant was mixed with the same volume of Griess reagent $[0.1 \%(\mathrm{w} / \mathrm{v}) \mathrm{N}$-(1-naphathyl)-ethylenediamine and $1 \%(\mathrm{w} / \mathrm{v})$ sulfanilamide in $5 \%(\mathrm{v} / \mathrm{v})$ phosphoric acid] for $10 \mathrm{~min}$ at room temperature. The absorbance of the final product was measured spectrophotometrically at $525 \mathrm{~nm}$ using an ELISA plate reader, and the nitrite concentration in the samples was determined from a standard curve of sodium nitrite made up in phenol red-free DMEM. The levels of $\mathrm{PGE}_{2}$, TNF- $\alpha$ or IL- $1 \beta$ present in each sample were determined using a commercially available kit from R\&D Systems (Abingdon, UK). The assay was performed according to the instructions provided by the manufacturer.

Western blot analysis. Western blot analysis was carried out as previously described (36). Western blot analysis was performed by lysing the cells in $20 \mathrm{mM}$ Tris- $\mathrm{HCl}$ buffer ( $\mathrm{pH}$ 7.4) containing a protease inhibitor mixture $(0.1 \mathrm{mM}$ PMSF, $5 \mathrm{mg} / \mathrm{ml}$ aprotinin, $5 \mathrm{mg} / \mathrm{ml}$ pepstatin $\mathrm{A}$ and $1 \mathrm{mg} / \mathrm{ml}$ chymostatin). The protein concentration was determined using a Lowry protein assay kit (P5626; Sigma Chemical Co.). An equal amount of protein for each sample was resolved by 12 or $7.5 \%$ sodium dodecyl sulfate-polyacrylamide gel electrophoresis (SDS-PAGE) and then electrophoretically transferred onto a Hybond enhanced chemiluminescence (ECL) nitrocellulose membrane (Bio-Rad, Hercules, CA, USA). The membrane was blocked with $5 \%$ skimmed milk and sequentially incubated with primary antibody (Santa Cruz Biotechnology, Inc.) and horseradish peroxidase-conjugated secondary antibody, followed by ECL detection (Amersham Pharmacia Biotech, Piscataway, NJ, USA).

Preparation of cytosolic and nuclear fractions. Preparation of cytosolic and nuclear fractions was carried out as previously described (37). The cells were collected and washed with phosphate-buffered saline (PBS) and suspended in $200 \mu \mathrm{llysis}$ buffer [10 mM HEPES (pH 7.9), $10 \mathrm{mM} \mathrm{KCl,} 0.1 \mathrm{mM}$ EDTA, $0.1 \mathrm{mM}$ EGTA, $1 \mathrm{mM}$ DTT, $1 \mathrm{mM}$ PMSF and a protease inhibitor cocktail]. The cells were allowed to swell on ice for 15 min; subsequently, $12.5 \mu 110 \%$ NP-40 was added. The tubes were agitated on a vortex for $10 \mathrm{sec}$ and then centrifuged for $5 \mathrm{~min}$. The resulting supernatant represented the cytosolic extract. The nuclear pellets were resuspended in $50 \mu \mathrm{l}$ ice-cold nuclear extraction buffer [20 mM HEPES (pH 7.9), $400 \mathrm{mM}$ $\mathrm{NaCl}, 1 \mathrm{mM}$ EDTA, $1 \mathrm{mM}$ EGTA, $1 \mathrm{mM}$ DTT, $0.5 \mathrm{mM}$ PMSF and a protease inhibitor cocktail] and incubated on ice for $1 \mathrm{~h}$ with intermittent vortexing. This nuclear extract was centrifuged for $10 \mathrm{~min}$ at $15,000 \mathrm{xg}$; the resulting supernatant represented the nuclear fraction.

$D N A$ binding activity of nuclear factor $-\kappa B(N F-\kappa B)$. As previously described (38), the DNA-binding activity of NF- $\mathrm{B}$ in the nuclear extracts was measured using a TransAM kit (Active Motif, Carlsbad, CA, USA) according to the manufacturer's instructions. Briefly, $30 \mu \mathrm{l}$ complete binding buffer (DTT, herring sperm DNA and binding buffer AM3) was added to each well. The samples were nuclear extracts of RAW264.7 macrophages that had been stimulated for $30 \mathrm{~min}$ with LPS and specific concentrations of DEE. Subsequently, the samples were diluted in complete lysis buffer and added to each well $(20 \mu \mathrm{g}$ nuclear extract diluted in complete lysis buffer to a final volume of $20 \mu \mathrm{l}$ ). The plates were incubated for $1 \mathrm{~h}$ at room temperature with mild agitation (100 rpm on a rocking platform). After washing each well with wash buffer, $100 \mu \mathrm{l}$ of diluted NF- $\kappa \mathrm{B}$ antibody (1:1,000 dilution in $1 \mathrm{X}$ antibody-binding buffer) was added to each well, and the plates were then further incubated, as previously described, for $1 \mathrm{~h}$. After washing each well with wash buffer, $100 \mu$ l diluted HRP-conjugated antibody $(1: 1,000$ dilution in $1 \mathrm{X}$ antibody-binding buffer) was added to each well followed by incubation for $1 \mathrm{~h}$, as before. Developing solution $(100 \mu \mathrm{l})$ was added to each well and left to react for $5 \mathrm{~min}$, followed by the addition of a stop solution to each well. Finally, the absorbance of each sample was read at $450 \mathrm{~nm}$ on a spectrophotometer (microplate reader model 680, serial no. 19590, Bio-Rad) within 5 min of reaction termination.

siRNA transfection of Nrf2. Cells were transiently transfected with Nrf2 siRNA (Santa Cruz Biotechnology, Inc.) for $6 \mathrm{~h}$ using Lipofectamine 2000 ${ }^{\mathrm{TM}}$ (Invitrogen, Carlsbad, CA, USA) according to the manufacturer's instructions, and then incubated in fresh media containing $10 \%$ FBS for $24 \mathrm{~h}$ before further manipulation.

Statistical analysis. Data are expressed as the means \pm SD of at least 3 independent experiments. To compare three or more groups, one-way analysis of variance (ANOVA) followed by a Newman-Keuls post hoc test was used. Statistical analysis was performed using GraphPad Prism software, version 3.03 (GraphPad Software Inc., San Diego, CA, USA).

\section{Results}

Inhibitory effects of DEE on the production of pro-inflammatory mediators and cytokines, and the expression of iNOS and COX-2 in LPS-stimulated RAW264.7 cells. We found that the Dojuksan $30 \%$ ethanol extract (DEE) was significantly more effective in terms of its anti-inflammatory effects than DWE (data not shown), and that it exerted its anti-inflammatory effects by inhibiting the expression of the pro-inflammatory enzymes, iNOS and COX-2, and suppressing the secretion of the pro-inflammatory cytokines, $\mathrm{NO}, \mathrm{PGE}_{2}, \mathrm{TNF}-\alpha$ and IL-1 $\beta$, through the inhibition of NF- $\kappa \mathrm{B}$ activation. Since DEE had more potent anti-inflammatory effects, it was used in our subsequent experiments. The cytotoxicity of DEE and DEE-5 in the RAW264.7 cells was determined by MTT assay. We found that cell viability was not significantly decreased by either DEE or DEE-5 at concentrations of up to $400 \mu \mathrm{g} / \mathrm{ml}$ (data not shown). Subsequently, we pre-treated the RAW264.7 cells with either $\mathrm{DEE}$ at non-cytotoxic concentrations (50-400 $\mu \mathrm{g} / \mathrm{ml})$ for $12 \mathrm{~h}$ and measured the production of NO, PGE 2 , TNF- $\alpha$ and IL- $1 \beta$ following stimulation with LPS $(1 \mu \mathrm{g} / \mathrm{ml})$ for $18 \mathrm{~h}$. With the increasing concentration of DEE, NO production decreased in 
A

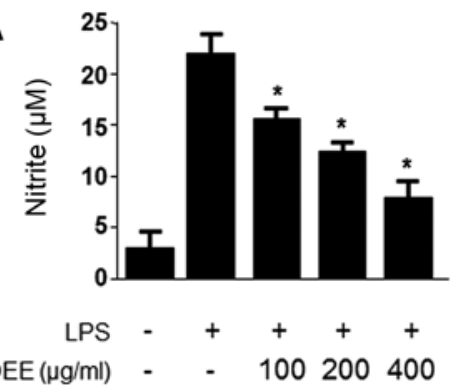

B

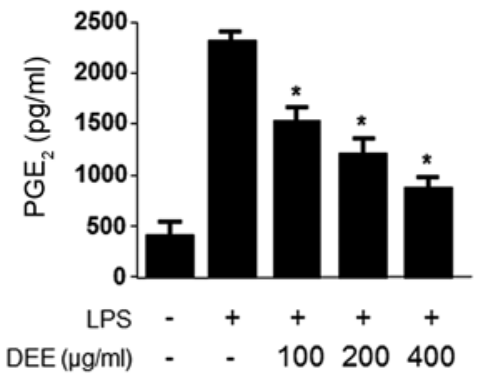

C

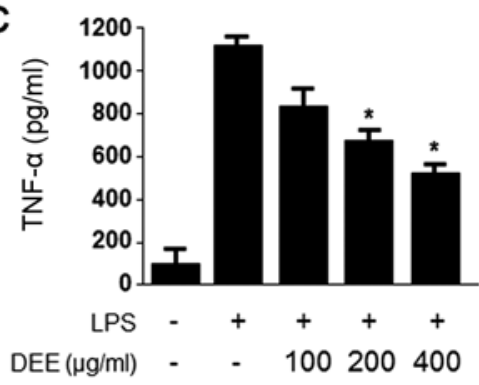

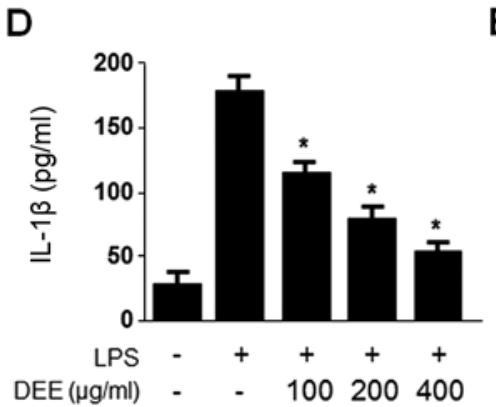
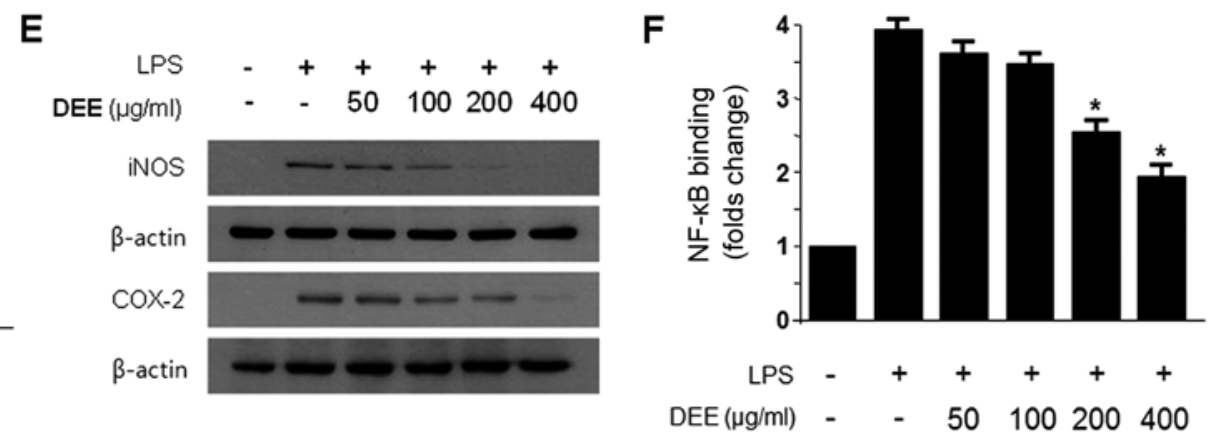

Figure 1. Effects of Dojuksan 30\% ethanol extract (DEE) on the production of (A) nitrite, (B) prostaglandin $\mathrm{E}_{2}\left(\mathrm{PGE}_{2}\right)$, (C) tumor necrosis factor- $\alpha$ (TNF- $\alpha$ ),

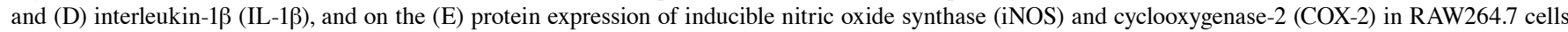
stimulated with lipopolysaccharide (LPS). (A-E) The cells were pre-treated for $12 \mathrm{~h}$ with the indicated concentrations of DEE and then stimulated for $18 \mathrm{~h}$ with LPS $(1 \mu \mathrm{g} / \mathrm{ml})$. (F) The cells were pre-treated for $12 \mathrm{~h}$ with the indicated concentrations of DEE and then stimulated for $30 \mathrm{~min}$ with LPS (1 $\mu \mathrm{g} / \mathrm{ml})$. The concentrations of nitrite, $\mathrm{PGE}_{2}, \mathrm{TNF}-\alpha$ and IL-1 $\beta$ were determined as described in the Materials and methods. Western blot analysis was performed, and representative blots of 3 independent experiments are shown. A commercially available nuclear factor- $\mathrm{kB}$ (NF- $\mathrm{kB}$ ) ELISA (active motif) was then used to test nuclear extracts and determine the degree of NF- $\mathrm{kB}$ binding. The data represent the means $\pm \mathrm{SD}$ of 3 independent experiments. " $\mathrm{p}<0.05$ compared with the group treated with LPS.

a dose-dependent manner until it reached a level close to that of the control cells (which were not treated with LPS) at $400 \mu \mathrm{g} /$ $\mathrm{ml}$. We observed a similar effect on the production of $\mathrm{PGE}_{2}$, TNF- $\alpha$ and IL-1 $\beta$ in the cells treated with DEE (Fig. 1).

The expression of the pro-inflammatory enzyme, iNOS, plays a crucial role in immune-activated macrophages through the production of NO $(26,27)$. In addition, prostaglandins are an important mediator of the symptoms of inflammation, including fever and pain. Inducible COX-2 is the major source of prostaglandins $(24,25)$. Thus, in order to examine the effects of DEE on the expression of iNOS and COX-2, the RAW264.7 cells were challenged with LPS $(1 \mu \mathrm{g} / \mathrm{ml})$ in combination with the indicated concentrations of DEE, and the protein expression levels of iNOS and COX-2 were measured by western blot analysis (Fig. 1E). DEE decreased both iNOS and COX-2 protein expression in a concentration-dependent manner.

$\mathrm{NF}-\kappa \mathrm{B}$ is a key molecule in an important signaling pathway involved in inflammatory diseases, and it regulates iNOS and genes, such as COX-2 $(39,40)$. Thus, to determine whether the $\mathrm{NF}-\mathrm{\kappa B}$ pathway is involved in the suppression of inflammatory responses by DEE, we measured NF-kB binding activity. DEE significantly decreased NF- $\mathrm{KB}$ binding activity in a concentration-dependent manner (Fig. 1D).

Effects of DEE on HO-1 expression are mediated by the nuclear translocation of Nrf 2 in RAW264.7 cells. We examined whether HO-1 is the key player mediating the DEE-induced suppression of pro-inflammatory responses. The RAW264.7 cells were treated with the indicated concentrations of DEE for $12 \mathrm{~h}$, or with $400 \mu \mathrm{g} / \mathrm{ml}$ of DEE for the indicated periods of time. We noted that DEE increased HO-1 expression in a concentrationdependent manner (Fig. 2A), and HO-1 expression began to increase $3 \mathrm{~h}$ following treatment with $400 \mu \mathrm{g} / \mathrm{ml}$ DEE (Fig. 2B). $\mathrm{Nrf} 2$ is as an indispensable regulator of the coordinated induction of phase II enzymes, including HO-1 (41). Therefore, we performed western blot analysis to determine whether treatment with DEE induces the nuclear translocation of Nrf2. When the cells were incubated with DEE for $0.5,1.0$ or $1.5 \mathrm{~h}$ at a concentration of $400 \mu \mathrm{g} / \mathrm{ml}$, there was a gradual increase in the levels of nuclear Nrf2, with a concomitant decrease in the cytoplasmic levels (Fig. 2C). The role of Nrf2 in DEE-mediated HO-1 expression was confirmed using siRNA against Nrf2. The RAW264.7 cells were transiently transfected with Nrf2 siRNA, and then treated with $400 \mu \mathrm{g} / \mathrm{ml}$ DEE for $12 \mathrm{~h}$. As shown in Fig. 2D, transient transfection with Nrf2 siRNA completely abolished DEE-induced HO-1 expression.

Effects of HO-1 expression on the inhibition of pro-inflammatory mediators, cytokines and $N F-\kappa B$ activity by DEE in LPS-stimulated RAW264.7 cells. To confirm the suppressive effects of HO-1 on pro-inflammatory mediators, cytokines and the NF- $\kappa B$ pathway, we used SnPP, which is a competitive inhibitor of $\mathrm{HO}$ activity. Previously, imidazole-dioxolane compounds have been shown to act as inhibitors of HO activity $(42,43)$, as well as specific $\mathrm{HO}$ isoenzymes (44). In the present study, RAW264.7 cells were pre-treated with DEE $(400 \mu \mathrm{g} / \mathrm{ml})$ for $12 \mathrm{~h}$ in the absence or presence of SnPP $(20 \mu \mathrm{M})$. The inhibitory effects of DEE on the LPS-induced production of NO, PGE $_{2}$, TNF- $\alpha$ and IL- $1 \beta$, as well as NF- $\mathrm{KB}$ binding activity, were partially reversed by SnPP (Fig. 3). 
A

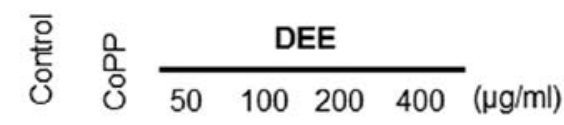

$\mathrm{HO}-1$

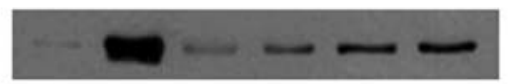

$\beta$-actin

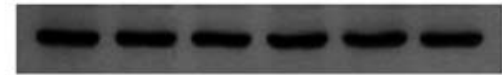

C

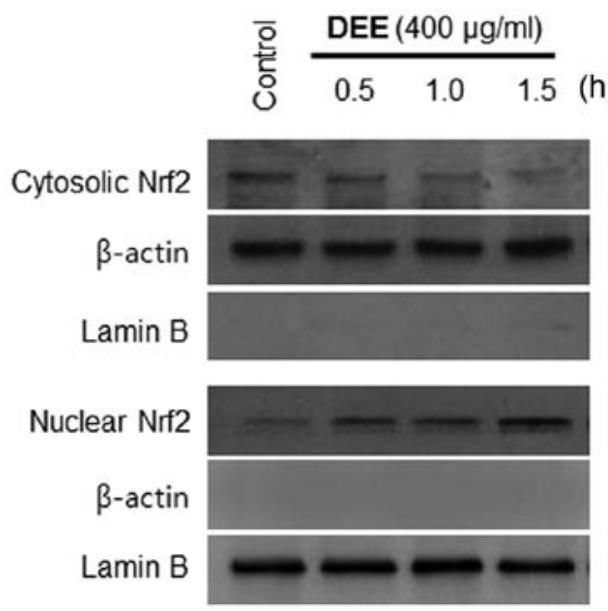

B

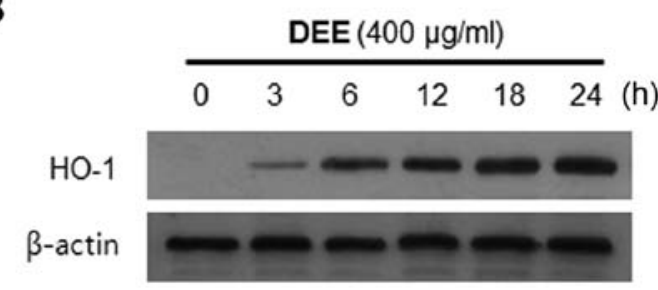

D

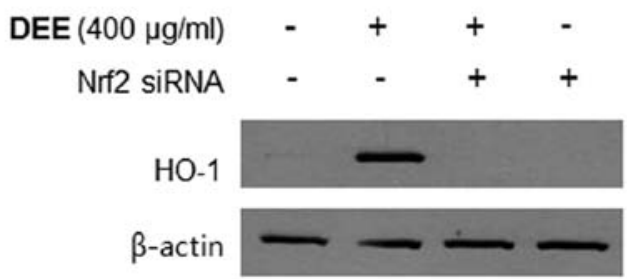

Figure 2. Effects of Dojuksan 30\% ethanol extract (DEE) on heme oxygenase-1 (HO-1) expression and the nuclear translocation of nuclear factor E2-related factor 2 (Nrf2) in RAW264.7 cells. The cells were incubated for $12 \mathrm{~h}$ with (A) the indicated concentrations of DEE, or (B) for the indicated periods of time with $400 \mu \mathrm{g} / \mathrm{ml}$ DEE. (C) The cells were treated for $0.5-1 \mathrm{~h}$ with $400 \mu \mathrm{g} / \mathrm{ml}$ DEE. (D) RAW264.7 cells were transiently transfected with Nrf2 siRNA, and treated with $400 \mu \mathrm{g} / \mathrm{ml}$ DEE for $12 \mathrm{~h}$. The positive control, the HO-1 inducer cobalt protoporphyrin IX (CoPP), increased the expression of HO-1 at $20 \mu \mathrm{M}$. Western blot analysis of HO-1 expression was performed as described in the Materials and methods, and representative blots of 3 independent experiments are shown.

A

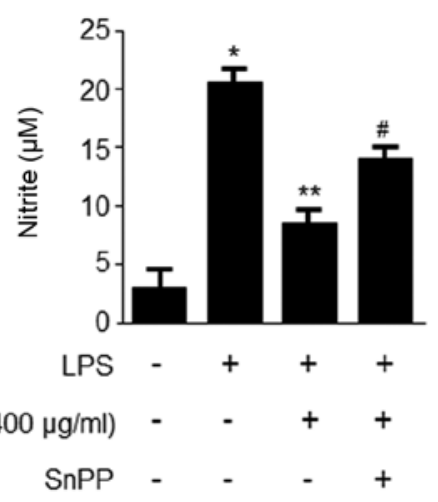

B

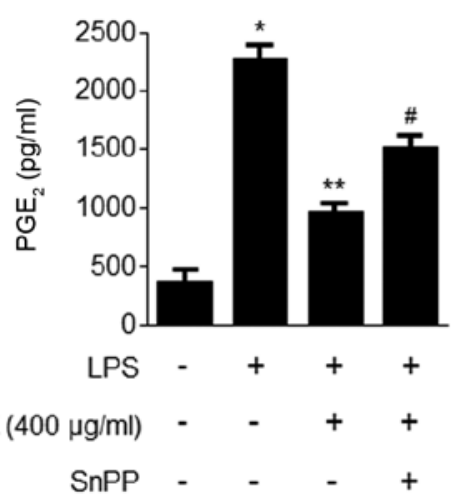

c

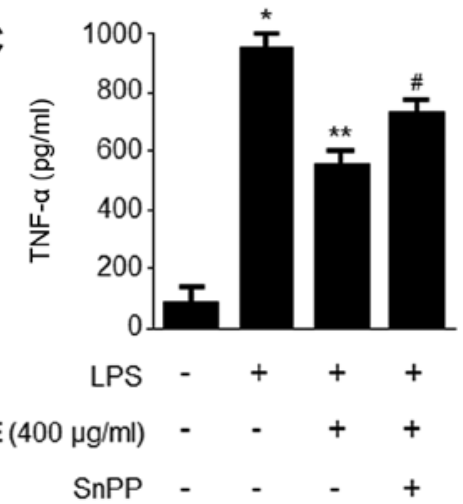

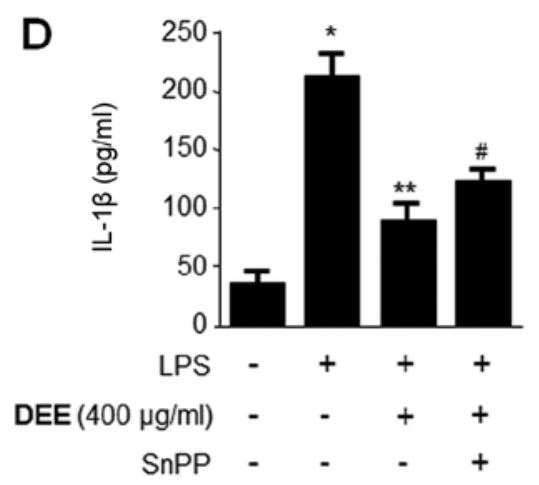

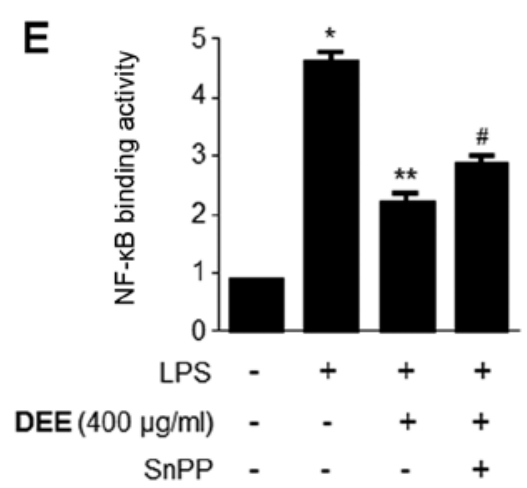

Figure 3. Effects of Tin-protoporphyrin IX (SnPP; HO-1 inhibitor) on Dojuksan 30\% ethanol extract (DEE)-mediated inhibition of (A) nitrite, (B) prosta-

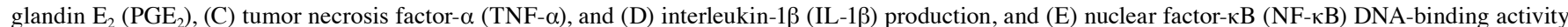
in lipopolysaccharide (LPS)-stimulated RAW264.7 cells. Cells were pre-treated with DEE $(400 \mu \mathrm{g} / \mathrm{ml})$ for $12 \mathrm{~h}$ in the presence or absence of SnPP $(50 \mu \mathrm{M})$,

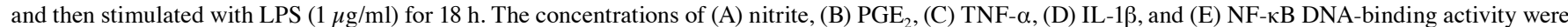
determined as described in Materials and methods. Data shown represent the means of 3 experiments \pm SD. ${ }^{*} \mathrm{p}<0.05$ compared to the control group; ${ }^{* *} \mathrm{p}<0.05$ compared to the group treated with LPS alone; ${ }^{\#} \mathrm{p}<0.05$ compared to the group treated with DEE and LPS. 


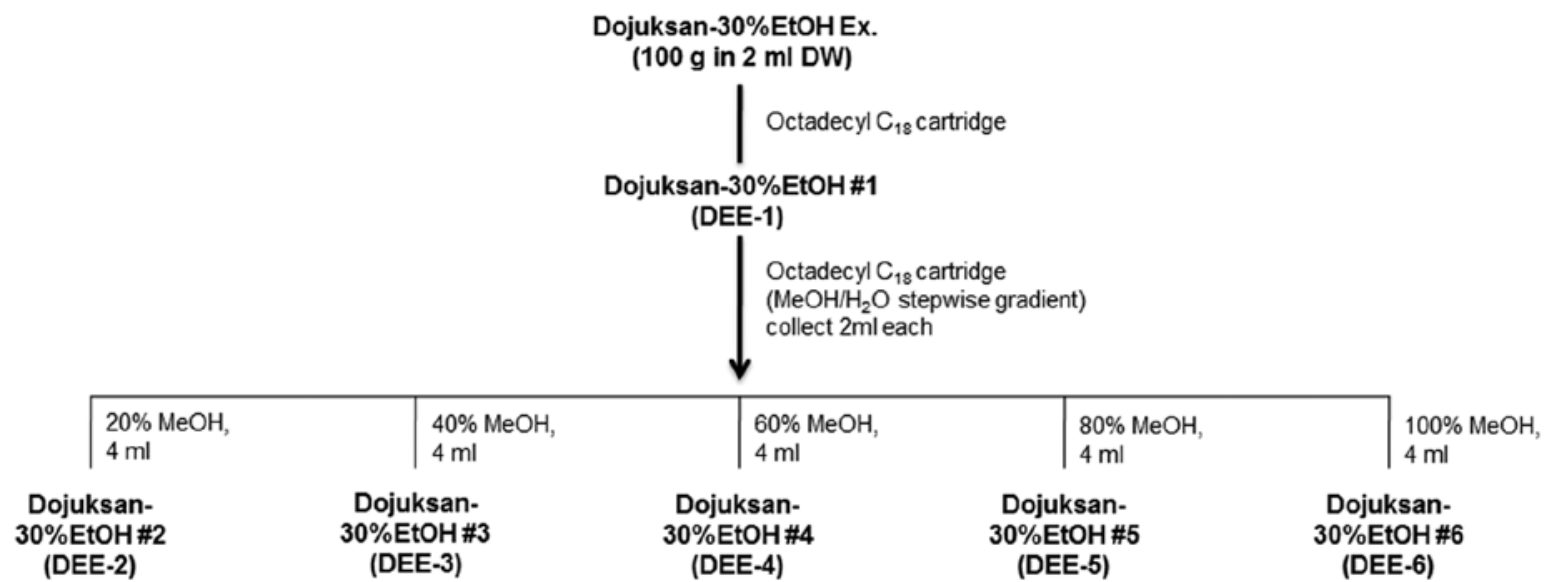

Figure 4. Fractions from $30 \%$ ethanol extract. The $30 \%$ ethanol extract was subjected to $\mathrm{C}_{18}$-functionalized silica gel flash column chromatography and eluted with a stepwise gradient of 0\% [Fr. 1, Dojuksan 30\% ethanol extract (DEE)-1], 20\% (Fr. 2, DEE-2), 40\% (Fr. 3, DEE-3), 60\% (Fr. 4, DEE-4), 80\% (Fr. 5, DEE-5), and $100 \%$ (Fr. 6, DEE-6) (v/v) of $\mathrm{MeOH}$ in $\mathrm{H}_{2} \mathrm{O}$ (4 ml each).
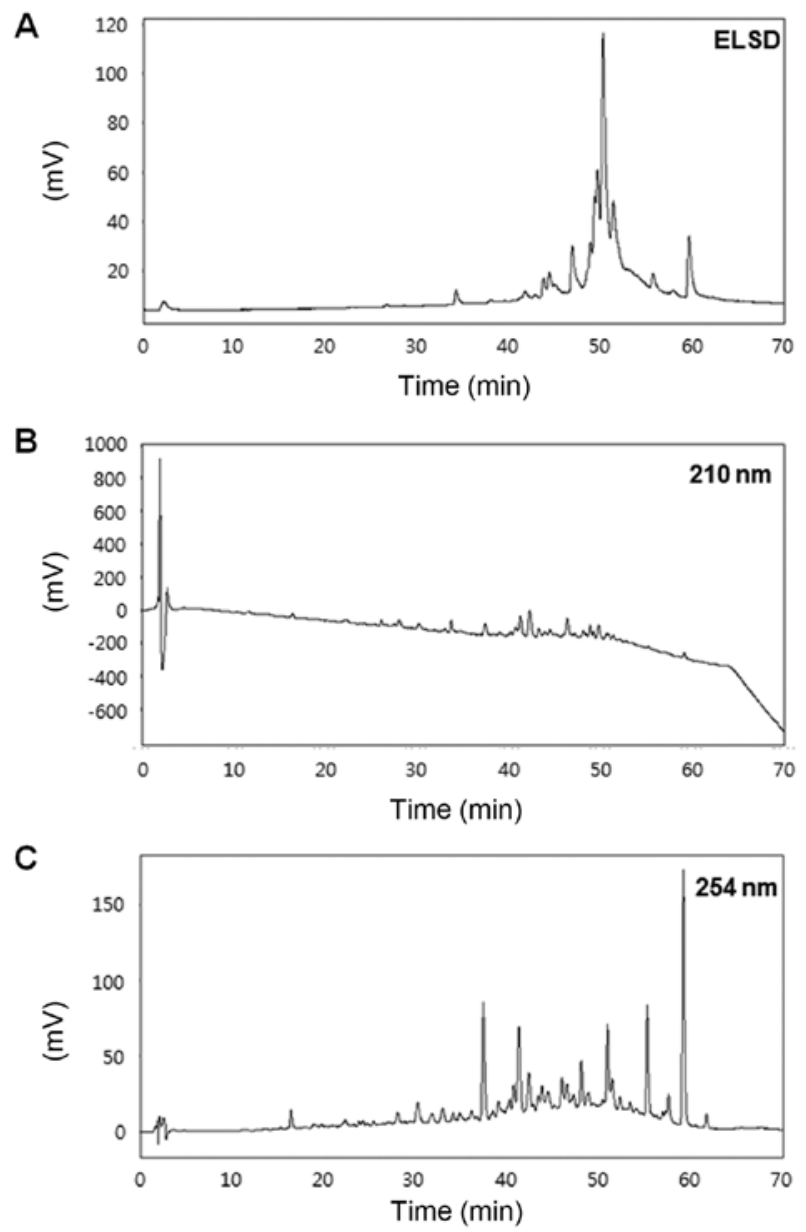

Figure 5. The HPLC chromatograms of DEE-5. HPLC chromatograms of DEE-5 were obtained using (A) an ELSD detector and (B) a UV/Vis detector operated at $210 \mathrm{~nm}$ or (C) $254 \mathrm{~nm}$.

Comparison of Dojuksan fractions by HPLC. To further explore the differences in the anti-inflammatory effects of DEE, we generated 6 different fractions of DEE using a $\mathrm{C}_{18}$ cartridge with a stepwise elution of $\mathrm{MeOH}$ in $\mathrm{H}_{2} \mathrm{O}$ (Fig. 4), as the HPLC chromatograms of DEE showed unclear patterns (data not shown). We then performed a comparative analysis of the HPLC chromatograms of each of the 6 fractions of DEE (Fig. 5). Data from the HPLC analysis of DEE-5 was obtained in the form of chromatograms by monitoring detector responses at ELSD, 210 and $254 \mathrm{~nm}$ (Fig. 5). Of the 6 fractions, DEE-5 induced the greatest decrease in NO production in the LPS-stimulated RAW264.7 cells (data not shown). Therefore, we further examined the anti-inflammatory effects of the Dojuksan ethanol extract using DEE-5.

Effects of DEE-5 on the inhibition of pro-inflammatory mediators and cytokines in LPS-stimulated RAW264.7 cells. To confirm the inhibitory effects of DEE-5 on pro-inflammatory mediators and cytokines, we pre-treated the RAW264.7 cells with DEE-5 (100 or $200 \mu \mathrm{g} / \mathrm{ml})$ for $12 \mathrm{~h}$ and then measured the protein expression of iNOS and COX-2, as well as the production of NO, PGE 2 , TNF- $\alpha$ and IL-1 $\beta$ following stimulation with LPS $(1 \mu \mathrm{g} / \mathrm{ml})$ for $18 \mathrm{~h}$. DEE-5 significantly decreased the protein expression of iNOS and COX-2, and the production of NO, $\mathrm{PGE}_{2}$, TNF- $\alpha$ and IL-1 $\beta$ (Fig. 6).

Effects of DEE-5 on HO-1 expression and the inhibition of pro-inflammatory mediators and cytokines in RAW264.7 cells. We also examined whether DEE-5 is able to induce the expression of HO-1. The RAW264.7 cells were treated with the indicated concentrations of DEE-5 for $12 \mathrm{~h}$, and we observed a significant increase in HO-1 expression at a concentration of 100-200 $\mu \mathrm{M}$ (Fig. 7A). The role of Nrf2 in DEE-5-mediated HO-1 expression was confirmed using siRNA against Nrf2. The RAW264.7 cells were transiently transfected with Nrf2 siRNA, and then treated with $200 \mu \mathrm{g} / \mathrm{ml}$ DEE- 5 for $12 \mathrm{~h}$. As shown in Fig. 7B, transient transfection with Nrf2 siRNA completely abolished DEE-5-induced HO-1 expression. To confirm the suppressive effects of HO-1 on pro-inflammatory mediators and cytokines, we used SnPP, which is a competitive inhibitor of HO activity. The RAW264.7 cells were pre-treated with DEE-5 $(200 \mu \mathrm{g} / \mathrm{ml})$ for $12 \mathrm{~h}$ in the absence or presence of SnPP. The inhibitory effects of DEE-5 on LPS-stimulated NO, $\mathrm{PGE}_{2}, \mathrm{TNF}-\alpha$, and IL-1 $\beta$ production were partially reversed by SnPP (Fig. 7C-F). 
A

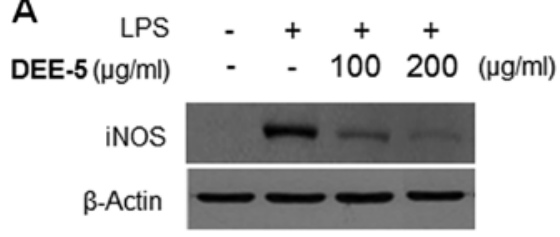

C

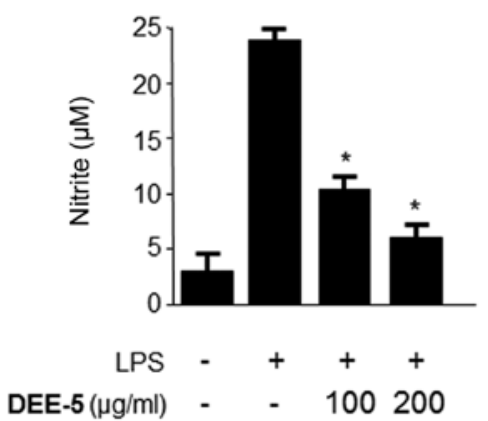

E

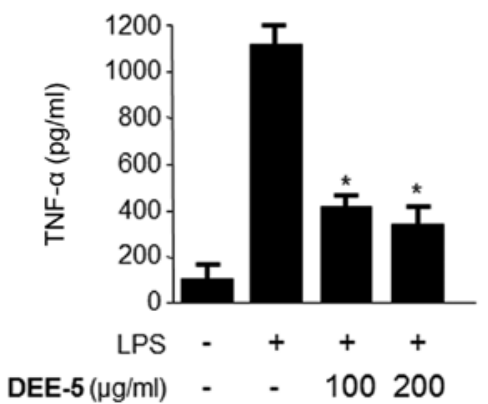

B

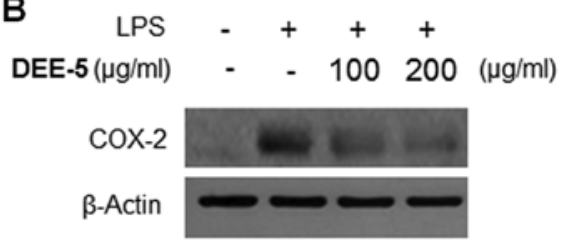

D

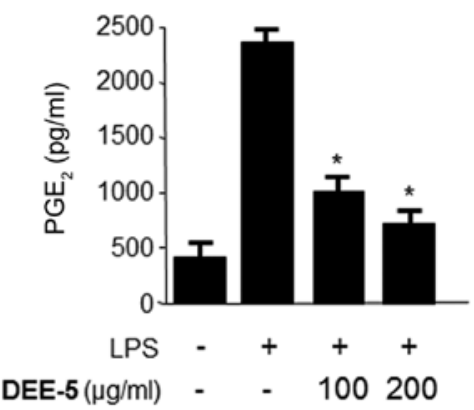

$\mathbf{F}$

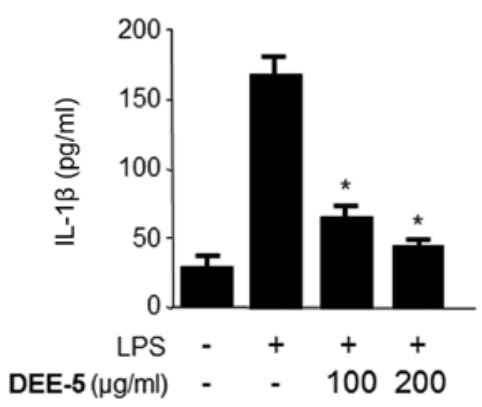

Figure 6. Effects of Dojuksan 30\% ethanol extract (DEE)-5 on the expression of (A) inducible nitric oxide synthase (iNOS) and (B) cyclooxygenase-2 (COX-2), and the production of $(\mathrm{C})$ nitrite, (D) prostaglandin $\mathrm{E}_{2}\left(\mathrm{PGE}_{2}\right)$, (E) tumor necrosis factor- $\alpha$ (TNF- $\alpha$ ), and (F) interleukin-1 $\beta$ (IL-1 $\beta$ ) in RAW264.7 cells stimulated with lipopolysaccharide (LPS). The cells were pre-treated for $12 \mathrm{~h}$ with the indicated concentrations of DEE-5 and then stimulated for $18 \mathrm{~h}$ with LPS $(1 \mu \mathrm{g} /$ $\mathrm{ml})$. Western blot analysis was performed, as described in the Materials and methods, and representative blots of 3 independent experiments are shown. The concentrations of nitrite, $\mathrm{PGE}_{2}$, TNF- $\alpha$ and IL-1 $\beta$ were determined. The data represent the means \pm SD of 3 independent experiments. "p $<0.05$ compared with the group treated with LPS.

\section{Discussion}

Dojuksan is a traditional herbal prescription medicine used in Korea and China to treat urinary diseases which cause symptoms, such as yellowish-red urine, pain in the phallus, dysuria and stomatitis (1). In a previous study (33), water extracts of Dojuksan inhibited inflammatory mediators in RAW264.7 cells. To date, and to the best of our knowledge, however, there have been few studies on Dojuksan, and no comparisons of the biological efficacy of Dojuksan extracts or its anti-inflammatory mechanisms have been made. In addition, our data suggested that DEE exerted a significantly more prominent anti-inflammatory effect than DWE (data not shown). Based on these findings, in the present study, we suggest a novel approach to understanding and improving the therapeutic effects of this traditional herbal formula.

Inflammation is a part of the complex biological response of the body to harmful stimuli, such as pathogens or irritants that have the capacity to cause cell damage (45). Inflammation is a protective attempt to remove injurious stimuli and to initiate the healing process by the organism. Various symptoms are associ- ated with inflammation, including flares, fever, swelling, itching and functional disorders caused by the induction of various pro-inflammatory mediators (46). It is well known that NO exerts broad physiological and pathological effects on a number of tissues, including immune cells. There are three well-known isoforms of NOS: nNOS, eNOS and iNOS (47). In lymphoid tissues, iNOS is the principal isoform of NOS. Macrophages appear to be a major source of iNOS $(26,47,48)$. iNOS differs from other NOS isoforms, since it is not constitutively present, but is instead induced by cytokines, such as interferon- $\gamma$ (IFN- $\gamma)$ and TNF- $\alpha$, or other immunological stimuli, including LPS. Prostaglandin endoperoxide $\mathrm{H}$ synthase and COX convert arachidonic acid (AA) to prostaglandin endoperoxide $\mathrm{H} 2$. Synthesized $\mathrm{PGH}_{2}$ is converted to prostaglandins $\left(\mathrm{PGD}_{2}\right.$, $\mathrm{PGE}_{2}$ and $\mathrm{PGF}_{2 \alpha}$ ), prostacyclin $\left(\mathrm{PGI}_{2}\right)$, or thromboxane $\mathrm{A} 2$ by tissue-specific isomerases (49). In the present study, we noted that DEE decreased iNOS and COX-2 protein expression and the production of pro-inflammatory cytokines, namely NO, PGE ${ }_{2}$ TNF- $\alpha$ and IL-1 $\beta$, in a concentration-dependent manner. Moreover, to examine whether NF- $\mathrm{BB}$ DNA-binding activity, a key signaling pathway leading to pro-inflammatory 
A
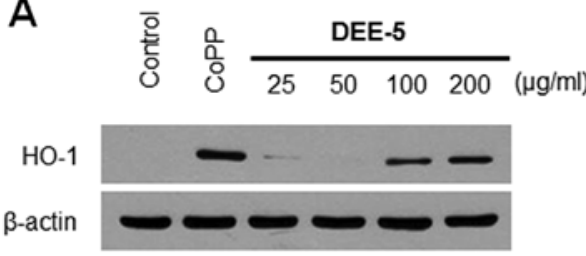

C

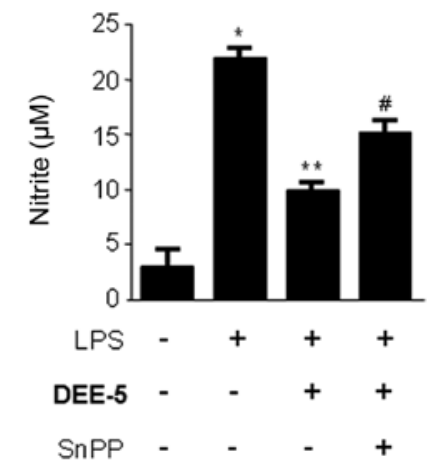

E

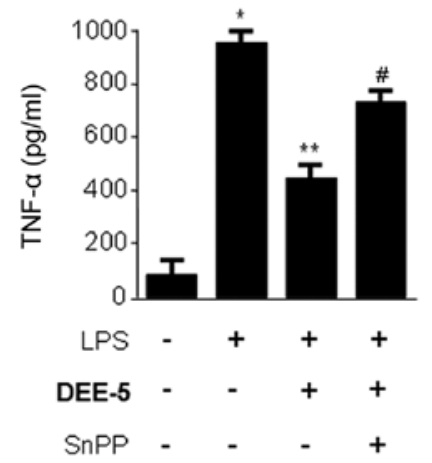

B

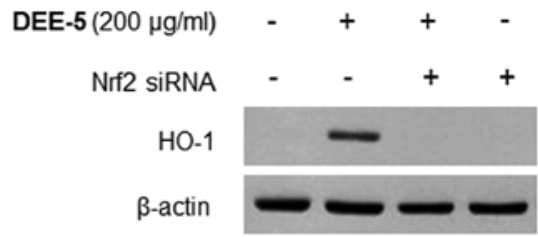

D

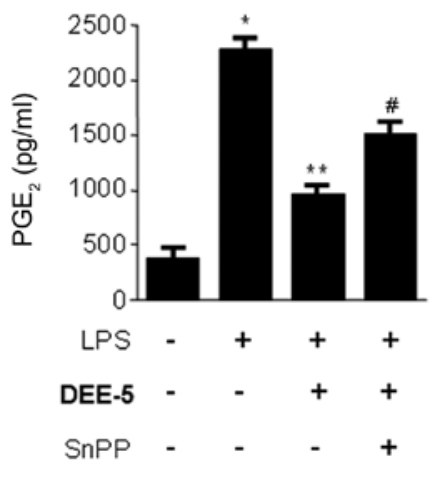

$\mathbf{F}$

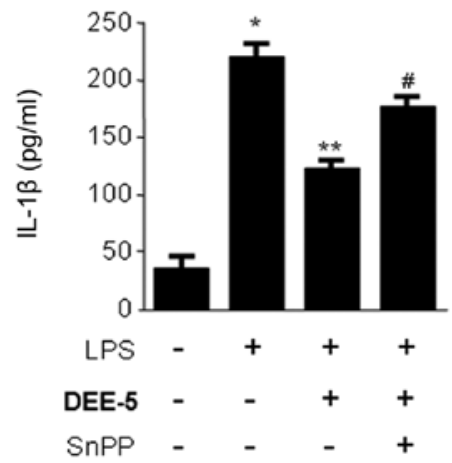

Figure 7. Effects of Dojuksan 30\% ethanol extract (DEE)-5 on (A and B) heme oxygenase-1 (HO-1) expression and (C) effects of Tin-protoporphyrin IX (SnPP; HO-1 inhibitor) on the DEE-5-mediated inhibition of nitrite, (D) prostaglandin $\mathrm{E}_{2}\left(\mathrm{PGE}_{2}\right)$, (E) tumor necrosis factor- $\alpha$ (TNF- $\alpha$ ), and (F) interleukin-1 $\beta$ (IL-1 $\beta$ ) production in RAW264.7 cells. (A) The cells were incubated for $12 \mathrm{~h}$ with the indicated concentrations of DEE-5. The positive control, the HO-1 inducer cobalt protoporphyrin IX (CoPP), increased the expression of HO-1 at $20 \mu \mathrm{M}$. (B) RAW264.7 cells were transiently transfected with nuclear factor E2-related factor 2 (Nrf2) siRNA, and then treated with $200 \mu \mathrm{g} / \mathrm{ml}$ DEE-5 for $12 \mathrm{~h}$. Western blot analysis of HO-1 expression was performed as described in the Materials and methods, and representative blots of three independent experiments are shown. Cells were pretreated with DEE-5 (200 $\mu \mathrm{g} / \mathrm{ml})$ for $12 \mathrm{~h}$ in the presence or absence of SnPP $(50 \mu \mathrm{M})$, and then stimulated with lipopolysaccharide (LPS) $(1 \mu \mathrm{g} / \mathrm{ml})$ for $18 \mathrm{~h}$. The concentrations of (C) nitrite, (D) PGE 2 , (E) TNF- $\alpha$, (F) IL-1 $\beta$ were determined as described in Materials and methods. Data shown represent the mean values of 3 experiments \pm SD. " $p<0.05$ compared to the control group; ${ }^{* *} \mathrm{p}<0.05$ compared to the group treated with LPS alone; ${ }^{*} \mathrm{p}<0.05$ compared to the group treated with DEE- 5 and LPS.

gene expression, is an upstream target for the inhibitory effects of DEE, we also examined the appearance of NF- $\mathrm{KB}$ DNA-binding activity. We noted that DEE inhibited the increase in NF- $\kappa B$ DNA-binding activity in RAW264.7 cells stimulated with LPS in a dose-dependent manner. In addition, as mentioned above, we found that DEE exerted a significantly more potent anti-inflammatory effect than DWE, and exerted its anti-inflammatory effects by inhibiting the expression of the pro-inflammatory enzymes, iNOS and COX-2, and suppressing the secretion of the pro-inflammatory cytokines, $\mathrm{NO}, \mathrm{PGE}_{2}$, TNF- $\alpha$ and IL-1 $\beta$, via the inhibition of NF- $\kappa B$ activation (data not shown). Therefore, we only used DEE in all our subsequent experiments.

Along with examining its antioxidant effects, recent studies have also demonstrated the anti-inflammatory effects of HO-1 reaction in a number of inflammatory models $(37,50)$. The antiinflammatory effects of HO-1 are mediated by inhibiting the production of pro-inflammatory cytokines and chemokines, such as TNF- $\alpha$, IL-1 $\beta$ and IL-6, in activated macrophages (51).
HO-1 and its product, carbon monoxide, can also suppress the expression of pro-inflammatory COX-2 and iNOS, thereby reducing COX-2-drived $\mathrm{PGE}_{2}$ and iNOS-derived NO production (52). Therefore, we suggest that regulating the degree of generation of oxidative stress and macrophage activation via the upregulation of HO-1 is an important aspect to be considered when formulating a strategy for treating inflammatory diseases. To determine whether HO-1, which is involved in both antioxidant and anti-inflammatory activities, is the key player in the DEE-mediated suppression of pro-inflammatory responses, we treated RAW264.7 cells with DEE and examined both tje concentration- and time-dependent effects. The expression of HO-1 increased as the concentration of DEE increased, and began to increase $3 \mathrm{~h}$ following treatment with $400 \mu \mathrm{g} / \mathrm{ml}$ DEE. To confirm the suppressive effects of HO-1 on pro-inflammatory mediators, we examined the effects of SnPP, which is a competitive inhibitor of HO-1 activity. The suppressive effects of DEE on LPS-induced NO, $\mathrm{PGE}_{2}, \mathrm{TNF}-\alpha$ and IL- $1 \beta$ production were partially reversed by SnPP. These 
results indicate that the inhibition of the pro-inflammatory mediators resulted, at least partially, from a stimulatory effect of DEE on HO-1. In addition, it has previously been noted that $\mathrm{Nrf} 2$ is an indispensable regulator of the coordinated induction of phase II enzyme genes, including HO-1 (41). Under normal homeostatic conditions, Nrf2 is retained in the cytoplasm via its interaction with Keap1 and is degraded by the proteasome. Under oxidative conditions, or as a result of specific stimuli, $\mathrm{Nrf} 2$ is released from Keap1, translocates to the nucleus, forms a heterodimer with small Maf proteins, and recognizes and binds to a cis-acting antioxidant response element (ARE), where it eventually recruits the transcriptional machinery, including RNA polymerase II, necessary for the transcription of its target genes $(31,32,52)$. In the present study, there was a gradual increase in Nrf2 levels in the nuclear fractions of the DEE-treated RAW264.7 cells, whereas the cytoplasmic levels were concomitantly decreased. This supports the hypothesis that Nrf2-mediated HO-1 expression contributes to the inhibitory effects of DEE on the production of pro-inflammatory mediators via the NF- $\mathrm{BB}$ pathway.

To further clarify the effects of Dojuksan, we also examined potential differences in the effects of DWE and DEE and examined whether the anti-inflammatory efficacy of the subfractions differed. We therefore generated 6 different fractions from DEE, and chromatographic analysis led to additional experiments using the $80 \% \mathrm{MeOH}$ fractions of DEE-5. Of the fractions, DEE-5 was responsible for the most significantly reduced NO production in the LPS-stimulated RAW264.7 cells (data not shown). Therefore, we further examined the anti-inflammatory effects of Dojuksan extracts using DEE-5. DEE-5 markedly suppressed the protein expression of iNOS and COX-2, and the production of NO, PGE $2, \mathrm{TNF}_{2} \alpha$ and IL-1 $\beta$. Furthermore, DEE-5 induced HO-1 protein expression, and the suppressive effects of DEE-5 on LPS-induced NO, $\mathrm{PGE}_{2}, \mathrm{TNF}-\alpha$ and IL-1 $\beta$ production were partially reversed by SnPP. These findings support the hypothesis that the induction of HO-1 contributes to the inhibitory effects of DEE-5 on the production of pro-inflammatory mediators.

In this study, we determined that the choice of extraction solvent affects the biological activity of Dojuksan, a traditional herbal formula. In conclusion, our results indicated that the Dojuksan $30 \%$ ethanol extract, and its fraction, exerted its antiinflammatory effects through Nrf2-mediated HO-1 expression, and that DEE likely has greater potential therapeutic applications than the water extract. We also suggest that the use of different extraction solvents or bioassay-guided fractionation is an option for improving the therapeutic efficacy of this traditional herbal formula.

\section{Acknowledgements}

This study was supported by Wonkwang University in 2013.

\section{References}

1. Sung SH, Lee SY, Kang OH, Kwon DY, Chong MS and Lee KN: Anti-allergic activity of Dojuk-San ethanol extract. Korean J Orient Physiol Pathol 25: 438-444, 2011.

2. Kim HM, An CS, Jung KY, Choo YK, Park JK and Nam SY: Rehmannia glutinosa inhibits tumour necrosis factor-alpha and interleukin-1 secretion from mouse astrocytes. Pharmacol Res 40: 171-176, 1999.
3. Tan W, Yu KQ, Liu YY, Ouyang MZ, Yan MH, Luo R and Zhao XS: Anti-fatigue activity of polysaccharides extract from Radix Rehmanniae Preparata. Int J Biol Macromol 50: 59-62, 2012.

4. Lau TW, Lam FF, Lau KM, Chan YW, Lee KM, Sahota DS, Ho YY, Fung KP, Leung PC and Lau CB: Pharmacological investigation on the wound healing effects of Radix Rehmanniae in an animal model of diabetic foot ulcer. J Ethnopharmacol 123: 155-162, 2009.

5. Lin AS, Qian K, Usami Y, Lin L, Itokawa H, Hsu C, Morris-Natschke SL and Lee KH: 5-Hydroxymethyl-2-furfural, a clinical trials agent for sickle cell anemia, and its mono/di-glucosides from classically processed steamed Rehmanniae Radix. J Nat Med 62: 164-167, 2008.

6. Lee HS, Kim ST and Cho DK: Effects of Rehmanniae radix water extract on renal function and renin secretion rate in unanesthetized rabbits. Am J Chin Med 21: 179-186, 1993.

7. Yokozawa T, Kim HY and Yamabe N: Amelioration of diabetic nephropathy by dried Rehmanniae Radix (Di Huang) extract. Am J Chin Med 32: 829-839, 2004.

8. Choi J, Jung HJ, Lee KT and Park HJ: Antinociceptive and antiinflammatory effects of the saponin and sapogenins obtained from the stem of Akebia quinata. J Med Food 8: 78-85, 2005.

9. Jung HJ, Lee CO, Lee KT, Choi J and Park HJ: Structure-activity relationship of oleanane disaccharides isolated from Akebia quinata versus cytotoxicity against cancer cells and NO inhibition. Biol Pharm Bull 27: 744-747, 2004.

10. Park HJ, Shim HS, Kim H, Kim KS, Lee H, Hahm DH and Shim I: Effects of Glycyrrhizae radix on repeated restraint stress-induced neurochemical and behavioral responses. Korean J Physiol Pharmacol 14: 371-376, 2010.

11. Zhang SP, Zhou YJ, Liu Y and Cai YQ: Effect of liquiritigenin, a flavanone existed from Radix glycyrrhizae on pro-apoptotic in SMMC-7721 cells. Food Chem Toxicol 47: 693-701, 2009.

12. Sekine-Osajima Y, Sakamoto N, Nakagawa M, Itsui Y, Tasaka M, Nishimura-Sakurai Y, Chen CH, Suda G, Mishima K, Onuki Y, et al: Two flavonoids extracts from Glycyrrhizae radix inhibit in vitro hepatitis C virus replication. Hepatol Res 39: 60-69, 2009.

13. Shin EM, Zhou HY, Guo LY, Kim JA, Lee SH, Merfort I, Kang SS, Kim HS, Kim S and Kim YS: Anti-inflammatory effects of glycyrol isolated from Glycyrrhiza uralensis in LPS-stimulated RAW264.7 macrophages. Int Immunopharmacol 8: 1524-1532, 2008.

14. Lee HY, Jung DY, Ha H, Kang SS, Kim JS and Kim C: Induction of growth hormone release by Glycyrrhizae radix on rat. J Biochem Mol Biol 40: 979-985, 2007.

15. Sato Y, Akao T, He JX, Nojima H, Kuraishi Y, Morota T, Asano T and Tani T: Glycycoumarin from Glycyrrhizae radix acts as a potent antispasmodic through inhibition of phosphodiesterase 3. J Ethnopharmacol 105: 409-414, 2006.

16. Lee HJ, Kim KA, Kang KD, Lee EH, Kim CY, Um BH and Jung SH: The compound isolated from the leaves of Phyllostachys nigra protects oxidative stress-induced retinal ganglion cells death. Food Chem Toxicol 48: 1721-1727, 2010.

17. Jung SH, Lee JM, Lee HJ, Kim CY, Lee EH and Um BH: Aldose reductase and advanced glycation endproducts inhibitory effect of Phyllostachys nigra. Biol Pharm Bull 30: 1569-1572, 2007.

18. Kim SH, Kim TS, Lee HJ and Yoo JC: Enhancement of 1,25-dihydroxyvitamin D3- and all-trans retinoic acid-induced differentiation of human leukemia HL-60 cells by Phyllostachys nigra var. henonis. Immunopharmacol Immunotoxicol 29: 119-129, 2007.

19. Kim SH, Kim TS, Kim SJ, Seong CN, Lee OH, Lee HJ and Yoo JC: Inhibition of interleukin-12 production in mouse macrophages via suppression of nuclear factor-kappaB binding activity by Phyllostachys nigra var. henonis. Immunopharmacol Immunotoxicol 29: 131-139, 2007.

20. Sachithanandan N, Graham KL, Galic S, Honeyman JE, Fynch SL, Hewitt KA, Steinberg GR and Kay TW: Macrophage deletion of SOCS1 increases sensitivity to LPS and palmitic acid and results in systemic inflammation and hepatic insulin resistance. Diabetes 60: 2023-2031, 2011.

21. Lee H, Bae S, Choi BW and Yoon Y: WNT/ $\beta$-catenin pathway is modulated in asthma patients and LPS-stimulated RAW264.7 macrophage cell line. Immunopharmacol Immunotoxicol 34: $56-65,2012$.

22. Karpurapu M, Wang X, Deng J, Park H, Xiao L, Sadikot RT, Frey RS, Maus UA, Park GY, Scott EW and Christman JW: Functional PU.1 in macrophages has a pivotal role in NF- $\kappa$ B activation and neutrophilic lung inflammation during endotoxemia. Blood 118: 5255-5266, 2011. 
23. Suh GY, Jin Y, Yi AK, Wang XM and Choi AM: CCAAT/enhancerbinding protein mediates carbon monoxide-induced suppression of cyclooxygenase-2. Am J Respir Cell Mol Biol 35: 220-226, 2006.

24. Samuelsson B, Morgenstern R and Jakobsson PJ: Membrane prostaglandin E synthase-1: a novel therapeutic target. Pharmacol Rev 59: 207-224, 2007.

25. Simmons DL, Botting RM and Hla T: Cyclooxygenase isozymes: the biology of prostaglandin synthesis and inhibition. Pharmaco Rev 56: 387-437, 2004.

26. Bogdan C: Nitric oxide and the immune response. Nat Immunol 2 : 907-916, 2001

27. Kobayashi Y: The regulatory role of nitric oxide in proinflammatory cytokine expression during the induction and resolution of inflammation. J Leukoc Biol 88: 1157-1162, 2010.

28. Tenhunen R, Marver HS and Schmid R: The enzymatic conversion of heme to bilirubin by microsomal heme oxygenase. Proc Natl Acad Sci USA 61: 748-755, 1968.

29. Tenhunen R, Marver HS and Schmid R: The enzymatic catabolism of hemoglobin: stimulation of microsomal heme oxygenase by hemin. J Lab Clin Med 75: 410-421, 1970.

30. Motterlini R, Haas B and Foresti R: Emerging concepts on the anti-inflammatory actions of carbon monoxide-releasing molecules (CO-RMs). Med Gas Res 2: 28, 2012.

31. Alam J, Stewart D, Touchard C, Boinapally S, Choi AM and Cook JL: Nrf2, a Cap'n'Collar transcription factor, regulates induction of the heme oxygenase-1 gene. J Biol Chem 274: 26071-26078, 1999.

32. Jaiswal AK: Regulation of genes encoding NAD(P)H:quinone oxidoreductases. Free Radic Biol Med 29: 254-262, 2000.

33. Kim JE, Kim SB, Kang OH, Shin IS, Kang SH, Lee SH and Kwon DY: Inhibitory effect of water extract from Dojuksan on LPS-induced proinflammatory cytokines production in RAW264.7 cells. Kor J Herbology 28: 53-60, 2013.

34. Choi HG, Lee DS, Li B, Choi YH, Lee SH and Kim YC: Santamarin, a sesquiterpene lactone isolated from Saussurea lappa, represses LPS-induced inflammatory responses via expression of heme oxygenase-1 in murine macrophage cells. Int Immunopharmacol 13: 271-279, 2012.

35. Titheradge MA: The enzymatic measurement of nitrate and nitrite. Methods Mol Biol 100: 83-91, 1998

36. Jeong GS, Lee DS and Kim YC: Cudratricusxanthone A from Cudrania tricuspidata suppresses pro-inflammatory mediators through expression of anti-inflammatory heme oxygenase-1 in RAW264.7 macrophages. Int Immunopharmacol 9: 241-246, 2009.

37. Lee DS, Kim KS, Ko W, Li B, Keo S, Jeong GS, Oh H and Kim YC: The neoflavonoid latifolin isolated from $\mathrm{MeOH}$ extract of Dalbergia odorifera attenuates inflammatory responses by inhibiting NF- $\mathrm{BB}$ activation via Nrf2-mediated heme oxygenase-1 expression. Phytother Res 28: 1216-1223, 2014.

38. Kim KS, Cui X, Lee DS, Sohn JH, Yim JH, Kim YC and Oh H: Anti-inflammatory effect of neoechinulin a from the marine fungus Eurotium sp. SF-5989 through the suppression of NF- $\kappa \mathrm{B}$ and p38 MAPK pathways in lipopolysaccharide-stimulated RAW264.7 macrophages. Molecules 18: 13245-13259, 2013.
39. Bonizzi G and Karin M: The two NF-kappaB activation pathways and their role in innate and adaptive immunity. Trends Immunol 25: 280-288, 2004.

40. Kim HG, Shrestha B, Lim SY, Yoon DH, Chang WC, Shin DJ, Han SK, Park SM, Park JH, Park HI, et al: Cordycepin inhibits lipopolysaccharide-induced inflammation by the suppression of NF-kappaB through Akt and p38 inhibition in RAW 264.7 macrophage cells. Eur J Pharmacol 545: 192-199, 2006.

41. Kensler TW, Wakabayashi N and Biswal S: Cell survival responses to environmental stresses via the Keap1-Nrf2-ARE pathway. Annu Rev Pharmacol Toxicol 47: 89-116, 2007.

42. Sugishima M, Higashimoto $Y$, Oishi $T$, Takahashi $H$, Sakamoto H, Noguchi M and Fukuyama K: X-ray crystallographic and biochemical characterization of the inhibitory action of an imidazole-dioxolane compound on heme oxygenase. Biochemistry 46: 1860-1867, 2007.

43. Vlahakis JZ, Kinobe RT, Bowers RJ, Brien JF, Nakatsu K and Szarek WA: Imidazole-dioxolane compounds as isozyme-selective heme oxygenase inhibitors. J Med Chem 49: 4437-4441, 2006.

44. Kinobe RT, Ji Y, Vlahakis JZ, Motterlini R, Brien JF, Szarek WA and Nakatsu K: Effectiveness of novel imidazole-dioxolane heme oxygenase inhibitors in renal proximal tubule epithelial cells. J Pharmacol Exp Ther 323: 763-770, 2007.

45. Ferrero-Miliani L, Nielsen OH, Andersen PS and Girardin SE: Chronic inflammation: importance of NOD2 and NALP3 in interleukin-1beta generation. Clin Exp Immunol 147: 227-235, 2007.

46. Mariathasan S and Monack DM: Inflammasome adaptors and sensors: intracellular regulators of infection and inflammation. Nat Rev Immunol 7: 31-40, 2007.

47. MacMicking J, Xie QW and Nathan C: Nitric oxide and macrophage function. Annu Rev Immunol 15: 323-350, 1997.

48. Liew FY and Cox FE: Nonspecific defence mechanism: the role of nitric oxide. Immunol Today 12: A17-A21, 1991.

49. O'Banion MK: Cyclooxygenase-2: Molecular biology, pharmacology, and neurobiology. Crit Rev Neurobiol 13: 45-82, 1999.

50. Lee DS, Ko W, Quang TH, Kim KS, Sohn JH, Jang JH, Ahn JS, Kim YC and Oh H: Penicillinolide A: a new anti-inflammatory metabolite from the marine fungus Penicillium sp. SF-5292. Mar Drugs 11: 4510-4526, 2013.

51. Lee DS, Li B, Im NK, Kim YC and Jeong GS: 4,2',5'-Trihydroxy4'-methoxychalcone from Dalbergia odorifera exhibits anti-inflammatory properties by inducing heme oxygenase-1 in murine macrophages. Int Immunopharmacol 16: 114-121, 2013.

52. Otterbein LE, Bach FH, Alam J, Soares M, Tao Lu H, Wysk M, Davis RJ, Flavell RA and Choi AM: Carbon monoxide has antiinflammatory effects involving the mitogen-activated protein kinase pathway. Nat Med 6: 422-428, 2000 